\title{
Diagnostic Performance of Imaging in Detection and Characterization of Liver Lesions
}

\author{
Hanady Elyas Abbas Osman ${ }^{1}$, Caroline Edward Ayad ${ }^{2}$ \\ ${ }^{I}$ (National Rabat University, College Of Medical Science And Nuclear Medicine-Khartoum-Sudan) \\ ${ }_{2}^{2}$ (Sudan University Of Science And Technology, College Of Medical Radiological Science Khartoum Sudan)
}

\begin{abstract}
The objective of this study was to evaluate the diagnostic performance of ultrasonography and contrast enhanced computed tomography (CT) in detection and characterization of liver lesions. Lesions in 50 patients were examined by sonography and contrast enhanced CT scan. The sonographic images were reviewed by sonologist and the specific diagnoses by $C T$ were recorded. The diagnostic performances including the characterization of each lesion enhancement as peripheral nodular enhancement, non enhance as well as shape including hypo dense non-enhancing focal lesions, as oval -shape hypo dense hepatic lesion, rounded hypo dense focal hepatic lesion were correlated with the final CT and Sonographic diagnosis .

After review of contrast-enhanced $C T$ scan images, the study revealed significant relation between the enhancement, character of the lesions and the sonographic findings with the CT diagnosis at $p<.001$ and $p<$ .001 and $p<0.017$ respectively. Contrast-enhanced CT improves the diagnostic performance in liver lesions compared with baseline sonography.
\end{abstract}

Keywords: CT diagnosis, liver lesion, sonography

\section{Introduction}

The diagnostic performance of liver imaging in patients with a history of known or suspected malignancy is essential because the liver is a common site of metastatic spread, and in patients with chronic liver disease who are at risk for developing carcinoma. Since benign liver lesions are common, liver imaging strategies should include liver lesion recognition and classification [1].Several imaging modalities are now available for detection and characterization of liver lesions. These include ultrasonography (US), computed tomography (CT), magnetic resonance imaging (MRI) and nuclear medicine.

It is recognized that the liver has a dual blood supply, the duration of the virtual hepatic arterial phase equals the interval from the beginning of the contrast inflow into the liver from arteries to the beginning of the contrast inflow from the portal vein [2,3,4].Using contrast agents can increase the detection and improve the characterization of focal liver lesions .For optimal lesion detection a good contrast-to noise ratio is essential since detection of these lesions depends mainly on contrast resolution. The contrast depends on the CT attenuation of the focal lesion but also on the liver parenchyma. [5] MDCT CT is the most commonly used imaging modality for both detection and characterization of hepatic metastases [5].

Fatty infiltration of the liver can result in decreased attenuation of the liver and lesion can become imperceptible or even appear hyper attenuating relative to the surrounding parenchyma. [6,7]. Authors prefer multiple contrast enhanced phases, depending on the indication, including three-phasic protocols evaluation of suspected of HCC [8]. Whether an unenhanced scan is still of value, is under discussion $[9,10]$. No or only limited role of unenhanced scan were found for the evaluation of hyper vascular or hypo vascular hepatic metastases [11, 12]. However, Oliver et al. (1998) [13] found that $28 \%$ of all hepatic metastases were seen only on the unenhanced scan. At our radiology departments unenhanced scan is performed in baseline studies, because the differentiation between cysts and small hypo vascular metastases and a delineation of calcifications and hemorrhage is improved Although the dynamic CT findings of HCC are well defined, there are few studies to compare imaging findings of HCCs of different etiologies [14,15]

Hemangiomas are often diagnosed by a single dynamic contrast enhanced CT scan. [16] Recent reports have recommended computed tomography (CT) as the primary radiologic method for the detection of suspected hepatic abscess. [17, 18] Despite this recommendation, the CT appearance of hepatic abscess has not been described in detail. In the only reported series with pathologic documentation, Rubinson et al [18] noted that intrahepatic abscess was often indistinguishable from simple hepatic cyst. However, the frequency of this occurrence was not specified.

Ultrasonography is a relatively inexpensive and noninvasive method of evaluating the upper abdomen. It is especially useful in evaluating for the presence of bile duct obstruction and the presence or absence of gallstones. Ultrasonography is especially useful in distinguishing between cystic and solid lesions.[19]US is widely available, and many clinicians request US as the initial imaging modality for the assessment of the upper 
abdomen including the liver to narrow down the differential diagnosis in a relatively quick and cost-effective manner.[20]

In the current study, we evaluated a triphasic spiral CT technique that allowed imaging of the entire liver in arterial, portal and equilibrium phases. The rationale behind the protocol is that the portal phase is the most sensitive phase for lesion detection, whereas the arterial and equilibrium phases can supply additional information on the vascularity of the lesion which may help to identify the nature of lesion.[21-25] The vascular hemodynamic is the key to detect characterization of hyper vascular lesions.

Several studies have been done worldwide on the role of triphasic CT scan in characterizing and differentiating benign and malignant lesions. However, to the best of our knowledge, no data has been published locally, so the purpose of this study was to describe the role of triphasic CT scan in liver lesions and to determine its diagnostic performance in characterization and differentiation liver lesion as it may be difficult to diagnose basing on one imaging study, because of the radiological similarities of lesions. [26] . In recent years many new imaging modalities have been introduced, including ultrasound (US). The question arises which imaging modality performs best in detection and characterization of hepatic lesions and whether we can rely on ultrasound as one of an imaging method for diagnosis liver lesion rather than to obtain CT scanning using radiation exposure. We reviewed the description of the typical features liver lesions on several imaging $\mathrm{CT}$ imaging phases and compared the findings with the character of the ultrasound findings.

\subsection{Patients and Methods}

\section{Materials and Methods}

The study was simultaneously conducted in Department of Diagnostic Radiology in CT department in Alfaisal Specialized Hospital, Ibn Alhaitham Diagnostic Centre, Antalya Medical Centre and Royal Care International Hospital. Data were collected from April 2014 to May 2016.

All the patients of age over 10 years with suspected liver disease were included in the study .By convenient sampling, 50 patients were collected from different male and female underwent CT triphaic scan. Distribution of study sample according to participant's age were $25-34$ years were $3(6 \%)$, 35-44 were 3(6\%) , $45-54$ were $9(18.0 \%) 55-64$ were $18(36 \%)$ and $>65$ were $17(34.0 \%)$ with mean age 59.28 \pm 12.67 , Minimum 27.00years, Maximum 85.00years, 22(44.0\%) were males and 28(56.0\%) were females.

The data that were collected from Alfaisal Specialized Hospital, the CT machine was Toshiba 4 slice (Asteion) using $120 \mathrm{KVP}, 200 \mathrm{MAS}$,also used triphasic protocol ( sure start protocol )manually taken one slice cut above the liver and then begin the scan early arterial phase, venous phase (portovenous phase) and delayed phase with automatic injection flow rate is $4 \mathrm{ml} / \mathrm{sec}$,and using 18 gague needle for injection .Patient position is supine position feet first. The data that collected from Royal Care International Hospital, the CT machine was Toshiba 64 slice (Aquilion) using $120 \mathrm{KVP}, 125 \mathrm{MAS}$, also used triphasic protocol begin the scan taken early arterial phase, venous phase (portovenous phase) and delayed phase with automatic injection using 70-100 ml omnipaque contrast media with flow rate is $3.5 \mathrm{ml} / \mathrm{sec}$. The scan begins immediately after injection and delayed phase are taken after $10 \mathrm{~min}$ from injection. Slice thickness $5 \mathrm{~mm} / \mathrm{slice}$, patient position is supine position feet first, the oral CM $500 \mathrm{ml}$ in 3 water bottle each one have $10 \mathrm{ml}$ of CM.

The data that collected from Ibn Alhaitham Diagnostic Centre, the CT machine are Toshiba 4 slice (Japan manufactures) using $120 \mathrm{KVP}, 187$ MAS ,also used triphasic protocol begin the scan taken early arterial phase(20sec from injection), venous phase $(40 \mathrm{sec})$ and delayed phase ( 5-10 min from injection ) with automatic injection using $75 \mathrm{ml}$ omnipaque contrast media $(40-50 \mathrm{ml}$ for child according to age and weight )for adult with flow rate is $3.5 \mathrm{ml} / \mathrm{sec}$.the scan begin immediately after injection and delayed phase are taken after $10 \mathrm{~min}$ from injection. Slice thickness $10 \mathrm{~mm} / \mathrm{slice}$, the oral CM $500 \mathrm{ml}$ in 3 water bottle each one have $10 \mathrm{ml}$ of CM. The first slice are the scout (coronal section) then take plain film without CM then scan triphasic protocol with CM.

Patient position is supine position feet first, from the sternal angle to symphysis pubis. In Antalya medical centre, the CT machine are bride speed 8 slice (American manufactures) using $120 \mathrm{KVP}, 165 \mathrm{MAS}$, the scout $120 \mathrm{KVP}$ and $10 \mathrm{MAS}$ also used triphasic protocol begin the scan taken arterial phase, venous phase and delayed phase (3-6 min from injection) with automatic injection using $75 \mathrm{ml}$ omnipaque contrast media for adult with flow rate is $3.5 \mathrm{ml} / \mathrm{sec}$. the scan begin immediately $5 \mathrm{~mm} /$ slice thickness then the reconstruction algorithm take $2.5 \mathrm{~mm}$.

The first slice are the scout ( coronal section)then take plain film without CM then scan triphasic protocol with CM .Abdominal ultrasound (US) was performed with phased array transducers operating between 3-5 MHz. Gray scale is an integral part of the examination of the liver, allowing demonstration of hepatic anatomy and pathology as the standard abdominal protocol [19] 


\subsection{Statistical analyses}

All data obtained in the study were documented and analyzed using SPSS program version 16. Descriptive statistics, including frequency and percentages, were calculated. ANOVA test was applied to test the significance of differences, $p$-value of less than 0.005 was considered to be statistically significant.

\section{Results}

Table 1 .Shows The Ultrasound Scanning Results (Liver Lesions And Associated Findings) Done For Patients Before The CT Scanning

\begin{tabular}{|c|c|c|}
\hline Diagnosis & Frequency & Percentages \% \\
\hline $\begin{array}{l}\text { Abdomino Pelvic Mass + Bilateral Ovarian Dermoid } \\
\text { Cysts }\end{array}$ & 1 & 2.0 \\
\hline Ascites + Hepatic Lesion & 24 & 48.0 \\
\hline Hepatic Lesion +Ca Prostate & 1 & 2.0 \\
\hline Fatty Liver & 1 & 2.0 \\
\hline Hepatocelluler carcinoma & 1 & 2.0 \\
\hline Hepatic Lesion + Adnexal Mass & 1 & 2.0 \\
\hline Hepatic Lesion + Heamoprotenium & 1 & 2.0 \\
\hline Hepatic Lesion + Hepatosplenomegaly & 3 & 6.0 \\
\hline Hepatic Lesion + Old TB Granuloma & 1 & 2.0 \\
\hline Hepatic Lesion + Sigmoid Tumor & 1 & 2.0 \\
\hline Hepatosplenomegaly + Portal Hypertension & 1 & 2.0 \\
\hline Hydatid Liver Cyst & 1 & 2.0 \\
\hline Liver Cyst & 2 & 4.0 \\
\hline Liver Mass & 2 & 4.0 \\
\hline Liver Metastases & 1 & 2.0 \\
\hline $\begin{array}{c}\text { Multiple Focal Sub-Diaphragmatic + Sub-Capsular } \\
\text { Lesions+ Multiple Mesenteric and Para-Aortic } \\
\text { Lymphadenopathies }\end{array}$ & 3 & 6.0 \\
\hline Hepatic Lesion +Pancreatic Tumor & 3 & 6.0 \\
\hline Liver Mass+ Right Inguinal Hernia & 1 & 2.0 \\
\hline Hepatic Lesion+ Right Renal Stone & 1 & 2.0 \\
\hline Total & 50 & 100.0 \\
\hline
\end{tabular}

Table 2. Shows the CT Scanning Results (Liver Lesions and Associated Findings)

\begin{tabular}{|c|c|c|}
\hline & Frequency & Percentages\% \\
\hline Cyst & 10 & 20.0 \\
\hline Cyst + Hepatitis & 1 & 2.0 \\
\hline Haemangioma & 7 & 14.0 \\
\hline $\begin{array}{c}\text { Haemangioma + Old Calcified } \\
\text { Granuloma }\end{array}$ & 1 & 2.0 \\
\hline Hepatocelluler carcinoma & 5 & 10.0 \\
\hline $\begin{array}{c}\text { Hepatocelluler carcinoma + Liver } \\
\text { Cirrhosis }\end{array}$ & 4 & 8.0 \\
\hline Hepatosplenomegaly & 1 & 2.0 \\
\hline Liver Abscess & 3 & 6.0 \\
\hline Liver Cirrhosis & 1 & 2.0 \\
\hline Liver Metastases & 15 & 30.0 \\
\hline Liver Mets + Hepatosplenomegaly & 1 & 2.0 \\
\hline Liver Metastases + Lymphoma & 1 & 2.0 \\
\hline Total & 50 & 100.0 \\
\hline
\end{tabular}

Table 3.Characterization of lesion contour by CT Scanning

\begin{tabular}{|c|c|c|}
\hline & Frequency & Percentages\% \\
\hline Hypo dense non-enhancing focal lesions & 15 & 30.0 \\
\hline Oval -shape hypo dense focal hepatic lesion & 8 & 16.0 \\
\hline Rounded hypo dense focal hepatic lesion & 27 & 54.0 \\
\hline Total & 50 & 100.0 \\
\hline
\end{tabular}

Table 4. Characterization of Lesion Enhancement by CT Scanning

\begin{tabular}{|c|c|c|}
\hline & Frequency & Percentages\% \\
\hline Peripheral Nodular Enhancement & 36 & 72.0 \\
\hline Non Enhance & 14 & 28.0 \\
\hline Total & 50 & 100.0 \\
\hline
\end{tabular}


Diagnostic Performance of imaging in detection and characterization of liver lesions

Table 5 .Enhancement patterns of the hepatic lesions cross tabulated with CT scanning diagnosis

\begin{tabular}{|c|c|c|c|}
\hline \multirow[b]{2}{*}{ CT (diagnosis) } & \multicolumn{2}{|c|}{ Enhancement pattern } & \multirow[b]{2}{*}{ Total } \\
\hline & Non Enhance & $\begin{array}{l}\text { Peripheral Nodular } \\
\text { Enhancement }\end{array}$ & \\
\hline \multirow{2}{*}{ Cyst } & 10 & - & 10 \\
\hline & $20.0 \%$ & - & $20.0 \%$ \\
\hline \multirow{2}{*}{ Cyst + Hepatitis } & 1 & - & 1 \\
\hline & $2.0 \%$ & - & $2.0 \%$ \\
\hline \multirow{2}{*}{ Haemangioma } & - & 7 & 7 \\
\hline & - & $14.0 \%$ & $14.0 \%$ \\
\hline \multirow{2}{*}{$\begin{array}{l}\text { Haemangioma + Old } \\
\text { Calcified Granuloma }\end{array}$} & - & 1 & 1 \\
\hline & - & $2.0 \%$ & $2.0 \%$ \\
\hline \multirow{2}{*}{ Hepatocelluler carcinoma } & - & 5 & 5 \\
\hline & - & $10.0 \%$ & $10.0 \%$ \\
\hline \multirow{2}{*}{$\begin{array}{c}\text { Hepatocelluler carcinoma + } \\
\text { Liver Cirrhosis }\end{array}$} & - & 4 & 4 \\
\hline & - & $8.0 \%$ & $8.0 \%$ \\
\hline \multirow{2}{*}{ Hepatosplenomegaly } & 1 & - & 1 \\
\hline & $2.0 \%$ & - & $2.0 \%$ \\
\hline \multirow{2}{*}{ Liver Abscess } & - & 3 & 3 \\
\hline & - & $6.0 \%$ & $6.0 \%$ \\
\hline \multirow{2}{*}{ Liver Cirrhosis } & 1 & - & 1 \\
\hline & $2.0 \%$ & - & $2.0 \%$ \\
\hline \multirow{2}{*}{ Liver Metastases } & 1 & 15 & 15 \\
\hline & $2.0 \%$ & $30.0 \%$ & $30.0 \%$ \\
\hline \multirow{2}{*}{$\begin{array}{c}\text { Liver Metastases }+ \\
\text { Hepatosplenomegaly }\end{array}$} & - & 1 & 1 \\
\hline & - & $2.0 \%$ & $2.0 \%$ \\
\hline \multirow{2}{*}{$\begin{array}{l}\text { Liver Metastases + } \\
\text { Lymphoma }\end{array}$} & - & 1 & 1 \\
\hline & - & $2.0 \%$ & $2.0 \%$ \\
\hline \multirow{2}{*}{ Total } & 14 & 36 & 50 \\
\hline & $28.0 \%$ & $72.0 \%$ & $100.0 \%$ \\
\hline $\mathrm{P}$-value & \multicolumn{3}{|c|}{0.001} \\
\hline
\end{tabular}

Table 6 .Characteristic Features of Detected Hepatic Lesions on CT cross tabulated with CT scanning diagnosis

\begin{tabular}{|c|c|c|c|c|}
\hline \multirow[b]{2}{*}{$\begin{array}{l}\text { CT Report } \\
\text { (Diagnosis) }\end{array}$} & \multicolumn{3}{|c|}{ Lesion Characteristics } & \multirow[b]{2}{*}{ Total } \\
\hline & $\begin{array}{l}\text { Hypo dense non- } \\
\text { enhancing focal } \\
\text { lesions }\end{array}$ & $\begin{array}{c}\text { Oval -shape } \\
\text { hypo dense focal } \\
\text { hepatic lesion }\end{array}$ & $\begin{array}{l}\text { Rounded hypo } \\
\text { dense focal } \\
\text { hepatic lesion }\end{array}$ & \\
\hline \multirow{2}{*}{ Cyst } & 10 & - & - & 10 \\
\hline & $20.0 \%$ & - & - & $20.0 \%$ \\
\hline \multirow{2}{*}{ Cyst + Hepatitis } & 1 & - & - & 1 \\
\hline & $2.0 \%$ & - & - & $2.0 \%$ \\
\hline \multirow{2}{*}{ Haemangioma } & - & 6 & 2 & 8 \\
\hline & - & $12.0 \%$ & $4.0 \%$ & $16.0 \%$ \\
\hline \multirow{2}{*}{$\begin{array}{l}\text { Hepatocelluler } \\
\text { Carcinoma }\end{array}$} & - & 2 & 3 & 5 \\
\hline & - & $4.0 \%$ & $6.0 \%$ & $10.0 \%$ \\
\hline \multirow{2}{*}{$\begin{array}{c}\text { Hepatocelluler } \\
\text { Carcinoma + Liver } \\
\text { Cirrhosis }\end{array}$} & - & - & 4 & 4 \\
\hline & - & - & $8.0 \%$ & $8.0 \%$ \\
\hline \multirow{2}{*}{ Hepatosplenomegaly } & 1 & - & - & 1 \\
\hline & $2.0 \%$ & - & - & $2.0 \%$ \\
\hline \multirow{2}{*}{ Liver Abscess } & - & - & 3 & 3 \\
\hline & - & - & $6.0 \%$ & $6.0 \%$ \\
\hline \multirow{2}{*}{ Liver Cirrhosis } & 1 & - & - & 1 \\
\hline & $2.0 \%$ & - & - & $2.0 \%$ \\
\hline \multirow{2}{*}{ Liver Metastases } & 2 & - & 13 & 15 \\
\hline & $4.0 \%$ & - & $26.0 \%$ & $30.0 \%$ \\
\hline \multirow{2}{*}{$\begin{array}{l}\text { Liver Metastases + } \\
\text { Hepatosplenomegaly }\end{array}$} & - & - & 1 & 1 \\
\hline & - & - & $2.0 \%$ & $2.0 \%$ \\
\hline \multirow{2}{*}{$\begin{array}{l}\text { Liver Metastases + } \\
\text { Lymphoma }\end{array}$} & - & - & 1 & 1 \\
\hline & - & - & $2.0 \%$ & $2.0 \%$ \\
\hline \multirow{2}{*}{ Total } & 15 & 8 & 27 & 50 \\
\hline & $30.0 \%$ & $16.0 \%$ & $54.0 \%$ & $100.0 \%$ \\
\hline P-value & \multicolumn{4}{|c|}{0.001} \\
\hline
\end{tabular}


Table 7. Ultrasonographic findings cross tabulated with CT scanning diagnosis

\begin{tabular}{|c|c|c|c|c|c|c|c|c|c|c|c|c|}
\hline \multirow[b]{2}{*}{$\begin{array}{l}\text { US Report } \\
\text { (Diagnosis) }\end{array}$} & \multirow[b]{2}{*}{ 党 } & \multirow[b]{2}{*}{ 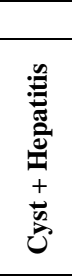 } & \multicolumn{9}{|c|}{ CT Report (Diagnosis) } & \multirow[b]{2}{*}{$\stackrel{\bar{\pi}}{0}$} \\
\hline & & & 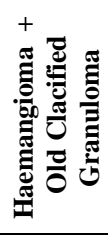 & U્త & 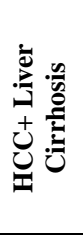 & 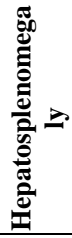 & 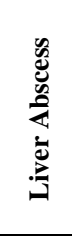 & 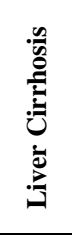 & 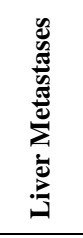 & 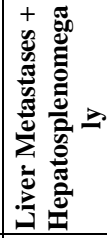 & 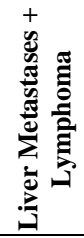 & \\
\hline \multirow{2}{*}{$\begin{array}{c}\text { Abdomino } \\
\text { pelvic mass } \\
\text { + ovarian } \\
\text { Dermoid } \\
\text { cysts/ } \\
\text { adenexia } \\
\end{array}$} & - & - & 1 & - & - & - & - & - & 1 & - & - & 2 \\
\hline & - & - & $2.0 \%$ & - & - & - & - & - & $2.0 \%$ & - & - & $4.0 \%$ \\
\hline \multirow{2}{*}{$\begin{array}{c}\text { Ascites/ } \\
\text { hepatic } \\
\text { lesion }\end{array}$} & 6 & 1 & 4 & 4 & 2 & - & 2 & - & 5 & - & - & 23 \\
\hline & $12.0 \%$ & $2.0 \%$ & $8.0 \%$ & $\begin{array}{c}8.0 \\
\%\end{array}$ & $4.0 \%$ & - & $4.0 \%$ & - & $10.0 \%$ & - & - & $48.0 \%$ \\
\hline \multirow{2}{*}{$\begin{array}{l}\text { Liver } \\
\text { Lesions+Ca } \\
\text { prostate }\end{array}$} & - & - & - & - & - & - & - & - & 1 & - & - & 1 \\
\hline & - & - & - & - & - & - & - & - & $2.0 \%$ & - & - & $2.0 \%$ \\
\hline \multirow[b]{2}{*}{ fatty liver } & - & - & - & - & - & 1 & - & - & - & - & - & 1 \\
\hline & - & - & - & - & - & $\begin{array}{c}2.0 \\
\% \\
\end{array}$ & - & - & - & - & - & $2.0 \%$ \\
\hline \multirow{2}{*}{$\mathrm{HCC}$} & - & - & 1 & - & - & - & - & - & - & - & - & 1 \\
\hline & - & - & $2.0 \%$ & - & - & - & - & - & - & - & - & $2.0 \%$ \\
\hline \multirow{2}{*}{$\begin{array}{c}\text { hepatic } \\
\text { lesion }+ \\
\text { heamoprote } \\
\text { nium }\end{array}$} & - & - & 1 & - & - & - & - & - & - & - & - & 1 \\
\hline & - & - & $2.0 \%$ & - & - & - & - & - & - & - & - & $2.0 \%$ \\
\hline \multirow{2}{*}{$\begin{array}{c}\text { hepatic } \\
\text { lesion }+ \\
\text { hepatosplen } \\
\text { omegaly }\end{array}$} & - & - & 1 & - & - & - & - & - & 1 & 1 & - & 3 \\
\hline & - & - & $2.0 \%$ & - & - & - & - & - & $2.0 \%$ & $2.0 \%$ & - & $6.0 \%$ \\
\hline \multirow{2}{*}{$\begin{array}{c}\text { hepatic } \\
\text { lesion }+ \\
\text { Old TB } \\
\text { granuloma } \\
\end{array}$} & - & - & - & 1 & - & - & - & - & - & - & - & 1 \\
\hline & - & - & - & $\begin{array}{c}2.0 \\
\%\end{array}$ & - & - & - & - & - & - & - & $2.0 \%$ \\
\hline \multirow{2}{*}{$\begin{array}{c}\text { hepatic } \\
\text { lesion }+ \\
\text { sigmoid } \\
\text { tumor }\end{array}$} & - & - & - & - & - & - & - & - & 1 & - & - & 1 \\
\hline & - & - & - & - & - & - & - & - & $2.0 \%$ & - & - & $2.0 \%$ \\
\hline \multirow{2}{*}{$\begin{array}{c}\text { hepatosplen } \\
\text { omegaly + } \\
\text { portal } \\
\text { hypertensio } \\
\text { n }\end{array}$} & - & - & - & - & 1 & - & - & - & - & - & - & 1 \\
\hline & - & - & - & - & $2.0 \%$ & - & - & - & - & - & - & $2.0 \%$ \\
\hline \multirow{2}{*}{$\begin{array}{l}\text { Hydatid } \\
\text { liver cyst }\end{array}$} & 1 & - & - & - & - & - & - & - & - & - & - & 1 \\
\hline & $2.0 \%$ & - & - & - & - & - & - & - & - & - & - & $2.0 \%$ \\
\hline \multirow{2}{*}{ liver cyst } & 1 & - & - & - & - & - & 1 & - & - & - & - & 2 \\
\hline & $2.0 \%$ & - & - & - & - & - & $2.0 \%$ & - & - & - & - & $4.0 \%$ \\
\hline \multirow{2}{*}{ liver mass } & - & - & - & - & - & - & - & - & 2 & - & - & 2 \\
\hline & - & - & - & - & - & - & - & - & $4.0 \%$ & - & - & $4.0 \%$ \\
\hline \multirow{2}{*}{$\begin{array}{c}\text { liver } \\
\text { metastases }\end{array}$} & - & - & - & - & - & - & - & - & 1 & - & - & 1 \\
\hline & - & - & - & - & - & - & - & - & $2.0 \%$ & - & - & $2.0 \%$ \\
\hline \multirow[b]{2}{*}{$\begin{array}{c}\text { multiple } \\
\text { focal sub- } \\
\text { diaphragma } \\
\text { tic + sub- } \\
\text { capsular } \\
\text { lesions } \\
\text { multiple } \\
\text { mesenteric } \\
\text { + para- } \\
\text { aortic } \\
\text { lymphaden } \\
\text { opathies } \\
\end{array}$} & - & - & - & - & 1 & - & - & 1 & - & - & 1 & 3 \\
\hline & - & - & - & - & $2.0 \%$ & - & - & $2.0 \%$ & - & - & $2.0 \%$ & $6.0 \%$ \\
\hline \multirow{2}{*}{$\begin{array}{c}\text { pancreatic } \\
\text { tumor } \\
\text { +multiple } \\
\text { hepatic } \\
\text { lesion }\end{array}$} & 2 & - & - & - & - & - & - & - & 1 & - & - & 3 \\
\hline & $4.0 \%$ & - & - & - & - & - & - & - & $2.0 \%$ & - & - & $6.0 \%$ \\
\hline
\end{tabular}


Diagnostic Performance of imaging in detection and characterization of liver lesions

\begin{tabular}{|c|c|c|c|c|c|c|c|c|c|c|c|c|}
\hline \multirow{2}{*}{$\begin{array}{c}\text { Right } \\
\text { inguinal } \\
\text { hernia }+ \\
\text { liver mass }\end{array}$} & - & - & - & - & - & - & - & - & 1 & - & - & 1 \\
\hline & - & - & - & - & - & - & - & - & $2.0 \%$ & - & - & $2.0 \%$ \\
\hline \multirow{2}{*}{$\begin{array}{c}\text { RT renal } \\
\text { stone+ } \\
\text { hepatic } \\
\text { lesion }\end{array}$} & - & - & - & - & - & - & - & - & 1 & - & - & 1 \\
\hline & - & - & - & - & - & - & - & - & $2.0 \%$ & - & - & $2.0 \%$ \\
\hline \multirow[b]{2}{*}{ Total } & 10 & 1 & 8 & 5 & 4 & 1 & 3 & 1 & 15 & 1 & 1 & 50 \\
\hline & $20.0 \%$ & $2.0 \%$ & $16.0 \%$ & $\begin{array}{c}10.0 \\
\%\end{array}$ & $8.0 \%$ & $\begin{array}{c}2.0 \\
\%\end{array}$ & $6.0 \%$ & $2.0 \%$ & $30.0 \%$ & $2.0 \%$ & $2.0 \%$ & $100.0 \%$ \\
\hline
\end{tabular}

\section{Discussion}

The goal of imaging in patients with liver lesions is essential in detection and characterization of those lesions. Patients with hepatic malignancy undergo CT examinations to exclude the presence of metastases and to evaluate the extent of local involvement. Diagnostic criteria for benign and malignant focal liver lesions on baseline ultrasound imaging was mentioned previously [27] Hemangioma is homogeneous echogenic lesion, echogenic peripheral rim with no or few peripheral or intralesional flow signals, liver abscess is thick irregular wall, internal anechogenicity or debris, flow signals in the wall liver metastases is heterogeneous echogenic lesion, hypoechoic rim, peripheral or internal arterial flow signals. Liver metastasis is heterogeneous echogenic lesion, hypoechoic halo, target sign, no or few peripheral flow signals[27]

Table (1) presented the ultrasound scanning results (liver lesions and associated findings) done for patients before the CT scanning and the data were presented in frequency and percentages. In our cases liver lesions were detected by ultrasonography and were diagnosed according to the above criteria[27]; however lesions were not mentioned specifically ; but only it was reported as liver lesions, as well, table( 2) shows the CT scanning results of liver lesions and associated findings .

Hepatic lesions are difficult to distinguish with imaging criteria alone, however certain focal liver lesions have classic ultrasonic, computed tomographic (CT) characteristics [28] It is important to emphasize that the primary objective in imaging the liver is to distinguish benign from metastatic and primary malignant lesion1 [28].Currently, there is no consensus concerning the optimal strategy for imaging the liver for focal liver disease.

Therefore in our study, tables $(2,3)$ characterized the liver lesion after contrast enhancement according to the shape and enhancement pattern. Our study was interpreted by one radiologist; the enhancement characteristics were assessed by grading the attenuation in comparison to liver parenchyma. Images were reviewed for the presence of focal liver lesions. The appearance of each lesion was described on the basis of the attenuation and the homogeneity of the lesion in comparison to surrounding parenchyma and was expressed as one of the possible states, a) area of water attenuation, homogeneous: hypo dense including (cyst), b) area of soft-tissue attenuation, often slightly inhomogeneous: hypo dense c )area of hyper attenuation,: hyper dense and d) iso attenuating compared e) moreover, the presence of a continuous, hyper attenuation peripheral $\mathrm{rim} / \mathrm{hypo}$ attenuating rim, hyper-(rim)/hypo-rim or non enhance were registered.

In our study we used the spiral computed tomography (CT) because it has gained approval as the favorite CT technique for routine liver evaluation because it provides image acquisition at peak enhancement of the liver parenchyma [29-32]. In addition, the fast data acquisition allows successive scanning of the entire liver at different moments after injection of contrast material, thus creating the possibility of multiphasic liver CT. In our cases multiple of liver lesions were detected as presented in table (2) similarly recent studies have reported an improvement in lesion detection when imaging is performed using contrast enhancement patterns especially in the presence of hyper vascular neoplasm, such as hepatocellular Carcinoma (HCC) [33-36].According to the literature and previous experience with dynamic liver CT, many different enhancement patterns were defined [37-39]

Imaging plays an essential role in diagnosis and management of patients with hepatocellular carcinoma. Although ultrasound is currently the main examination imaging tool for HCC [40], dynamic crosssectional CT imaging techniques were also applied for diagnosis and staging of HCC. This is supported by the current technical advances on the CT concerning reduction of radiation exposure, optimization of tissue characterization, development of targeted contrast agents in different enhancement phase. Table $(5,6)$ presented the enhancement pattern of the HCC and the liver cirrhoses .A liver mass in a cirrhotic liver should be viewed as an HCC until proven otherwise. The diagnosis of liver masses in a cirrhotic liver includes malignant and benign lesions [34-36] After detecting hepatic mass on ultrasound, the mass was characterized with contrast enhanced multi detector computed tomography .Each modality has its own description of the hepatic lesion and cirrhosis depending on number of nodules and other factors [34]This current study showed the various characteristics of the liver masses /lesions in cirrhotic and non cirrhotic liver .HCC appears as peripheral 
enhancement. Cases with cysts appears as non enhanced in 11(22.0\%) of the cases as hypo dense nonenhancing focal lesions, similar description was presented in the study done by Premashis Kar et al 2011 [28] who mentioned that on CT; cysts appear as a well defined intrahepatic lesion having water attenuation $(0-15$ $\mathrm{HU}$ ), round or oval in shape with smooth thin walls and homogeneous appearance with no internal structures and no enhancement after contrast administration.

In the current study and regarding the liver abscess; it has been described as peripheral nodular enhancement, rounded hypo dense focal hepatic lesion in 3(6\%) of the cases. previous experience has shown that CT is the most accurate method of detection of liver abscess [18]. studies showed that the CT diagnosis of liver abscess has limitations. The $\mathrm{CT}$ appearance is often nonspecific and non diagnostic. In the series reported, abscesses varied in appearance from smoothly marginated, fluid-filled cavities to poorly defined masses with densities slightly less than surrounding liver. Similar results were reported in the series of Rubinson et aI.[41], in which findings reportedly suggestive of abscess is the demonstration of a hyper dense rim on CT after contrast enhancement this was similar to our study findings. CT diagnostic criterion: is that, not all abscesses exhibit rim enhancement. Allen [42] found a definable wall or rim in only $\mathbf{3 8 \%}$ of intraabdominal abscesses. In our study, rim enhancement was seen in 3 cases $(6 \%)$. The second problem is the non specificity of rim enhancement because both hyper vascular malignant tumors and hemangiomas may exhibit hyper dense peripheral rims. [42]. However in the current study Haemangiomas were found as peripheral nodular enhancement in $8(16 \%)$ of the cases, $6(12 \%)$ were oval -shape hypo dense focal hepatic lesion and $2(4 \%)$ were rounded hypo dense focal hepatic lesion after the enhanced CT scan. The usefulness of intravenous contrast media in the detection of liver abscess has been questioned by Rubinson et al. [18,41]. They mentioned that contrast enhancement provided no information that was not already available on unenhanced scans. However our experience differed: in our cases, the abscesses were detected more easily after contrast enhancement the difference in density between the normal and abnormal tissue increased with contrast medium administration. We therefore recommend the routine use of intravenous contrast media during CT evaluation for liver abscess.

Patients with a known or suspect to have hepatic malignancy should undergo abdominal survey examinations to look for liver metastases, lymph node involvement and local involvement.[43]

During our liver evaluation, our study main goal is to determine the presence/absence of hepatic metastases; such examinations were undertaken with a contrast-enhanced CT study since many previous studies have mentioned that CT has high sensibility and specificity for detecting hepatic metastases [44]. The study findings shows that most of the liver metastases were demonstrated to have peripheral nodular enhancement which were detected in $16(32 \%)$ of the cases $.2(4.0 \%)$ were hypo dense non-enhancing focal lesions and $14(28.0 \%)$ were rounded hypo dense focal hepatic lesion also the involvement of mesenteric and para aortic lymph nodes were detected and described during one CT contrast enhanced scan, this was presented in tables $(5,6)$.The current study findings acknowledged the significant relationship between the lesion character and shape and enhancement pattern with the CT diagnosis at $p \leq 0.000$

In the United States, metastatic disease is the most common cause of malignancy in the liver and is more common than primary liver cancer. The colon, stomach, pancreas, and breast are the most common primary sites.[28] In the current study the colon and pancreas were involved as affected with cancer ,this was diagnosed in both the CT contrast enhanced study and the US examination tables $(5,6,7)$.The appearance of a new lesion in the liver in a patient with a history of cancer strongly suggests hepatic metastasis. In most series, about one third of patients who die with a malignancy have liver involvement. [45,46]

Numerous imaging methods are available for detecting hepatic metastatic disease .The usefulness of various imaging modalities can vary significantly across institutions because of local radiological expertise, availability of equipment or personnel, and the wishes and biases of treating physicians and radiologists.[28]

Ultrasound (US) is the most available technique for liver imaging worldwide, and in many countries is the major modality used to search for liver metastases. In the United States, the relative availability of computed tomography (CT) and limited physician involvement in the performance of US, contribute to a lesser role for US diagnosis. Many patients have liver masses detected by US when suspicion of metastases is not high. In the United States screening for metastases is performed less often with US. Comparative studies demonstrate that US has high specificity but lower sensitivity than other imaging modalities [47, 48, 49] With US, metastases can be hypoechoic, hyperechoic, cystic, or diffuse. Metastases frequently displace normal liver vessels.

Our Radiologist suggested that patients with liver disease at risk for developing hepatocellular carcinoma should undergo periodic liver screening with US, and contrast-enhanced CT which is used for evaluating patients with an abnormal US. This is what was applied in our patients. Studies suggested that when CT is used to characterize a liver lesion detected with US, the CT examination should include arterial phase and portal venous phase imaging as many incidentally discovered liver lesions are hypervascular and therefore may be demonstrated and/or characterized accurately only if arterial phase imaging is included [50,51] 
When the ultrasound results were correlated with the CT scanning results it showed a significant relationship at $p \leq 0.017$.That means ultrasonography is acknowledged in detection and characterization of liver lesions. Because ultrasonography has excellent spatial and contrast resolution it may therefore provide useful information regarding the liver and liver masses without the use of contrast agents as CT scans. Liver cysts were identified and confidently diagnosed, and a variety of appearances of solid masses suggested a specific diagnosis. Recognition of a hypoechoic halo or rim surrounding an echogenic or isoechoic liver mass, suggested probable malignancy, this was also been mentioned in previous studies [52,53] and masses with this morphologic characteristic were provoked confirmatory imaging with computed tomographic (CT) scans, some showed similar findings and another showed different results as presented in table(7) .Multiple hypoechoic masses in the liver most often suggest metastases.[54]This was seen in our results and it was also diagnosed well in the contrast enhanced CT scans. By comparison, the common appearance of abdomino pelvic mass was diagnosed ultrasonographically with good evaluation of adenexia, it was found as a solid, uniformly echogenic mass, possibly showing increased enhancement deep to the mass, is so well recognized in $(1(2 \%)$ of the patients with hepatocellular carcinoma (HCC) and $1(2 \%)$ of the cases affected with metastases, the identification of such a mass rule out the need for CT imaging where the diagnoses was done regarding to its findings, similar results were reported in previous study. [55] However, in patients with $\mathrm{HCC}$, a variety of metastases from Ca colon, $\mathrm{Ca}$ pancreases ,Ca prostate were detected in our cases. Studies have mentioned that there is recognition that lesions with uniformly echogenic mass like may represent malignant liver tumors, [56] and confirmation of all such masses using CT scans was done and were significantly correlated with the findings, our study recommended to use the CT enhancement pattern in the detection and recognition of hepatic masses and lesions. This intense trust on clinical sequence has become part of our practice standard however it highlight the lack of specificity of ultrasonography. With knowledge of the patient's history, different interpretations may result from an identical ultrasonographic appearance. Studies have mentioned that in the cases of a mass like or hepatic lesions, interpretation tends to work relatively well in clinical practice, though it demonstrate the lack of a methodological basis on which the interpretations can be made in the absence of clinical information ,as well the diagnostic criteria of benignancy and malignancy on Ultrasonography showed be considered as homogeneous, hyperechogenicity, hypoechogenicity with hyperechoic rind, posterior enhancement, malignant, hypoechoic halo, target appearance and hypoechoic. HCC varied in characteristics and the Hemangioma was homogeneous, hyperechogenicity or hypoechoic, with hyperechoic rind or posterior enhancement. Metastasis were hypoechoic ,non- homogeneous echogenicity or Hypoechoic halo.In many other cases, a mass seen on ultrasonography is referred for contrast-enhanced CT for a confident diagnosis.[57]The assessment of the abdomen is the main role for CT examination, where the major indication is to detect or exclude and characterize focal liver lesions:- (1) in patients where a primary malignancy is already known in order to search for metastasis and (2) in individuals with a suspected tumor in order to discover the primary site of the malignancy.

Our study has some limitations: the small sample size especially for benign lesions. Interobserver agreement for interpretation of CT images was not calculated. In cases of focal lesion, biopsy was not performed but the diagnosis was based upon the radiologist opinion and the CT/Ultrasound diagnostic criteria. Other potential limitation is that scans were performed on different CT Scanners of different make.

\section{Conclusion}

MDCT is a technique with excellent spatial resolution, able to visualize the normal anatomy, as well as any pathologic changes and the relationship to surrounding structures .Additionally, MDCT scanning time has decreased allowing rapid accurate multiphasic imaging with short breath-holding periods. The combination of MDCT and the optimization of contrast-agent administration have significantly improved the quality of multiphasic liver imaging with respect to accurate depiction of enhancement as well as through-plane resolution. Using thinner slices able us to detect the small lesions. Whereas large tumors reveal typical patterns of morphology, attenuation and enhancement, small lesions still remain challenging even with MDCT, since the specific criteria for confident diagnosis become more ambiguous due to an inherent overlap of CT appearance among lesions.Due to the low costs and widespread availability of ultrasound (US), it always has to be taken into consideration for diagnosing focal liver lesions. However, despite recent improvements in sonographic equipment, US is still limited by its lack of sensitivity in the detection of flow in liver lesions, and the examination procedure is vulnerable by breathing artifacts. [59]

Finally, Contrast-enhanced CT improves the diagnostic performance in liver lesions compared with baseline sonography .MDCT of the abdomen generates a significant radiation dose to the patient. Thus, the number of necessary scans as well as the application of lower collimation should be strictly checked for each patient with respect to the individual clinical concern and history. 


\section{Acknowledgements}

We sincerely thank the participants without whom the study would not have been feasible. The Sudan University of Science and Technology, College of Medical Radiological Science and Radiology Department in Alfaisal Specialized Hospital, Ibn Alhaitham Diagnostic Centre, Antalya Medical Centre and Royal Care International Hospital are thankfully acknowledged.

\section{References}

[1]. Maria Raquel Oliva and Sanjay Saini,Liver cancer imaging: role of CT, MRI, US and PETCancer Imaging (2004) 4, S42-S46

[2]. Sun HC, Tang ZY (2003) Preventive treatments for recurrence after curative resection of hepatocellular carcinoma. A literature review of randomized control trials. World J Gastroenterol 9:635-640

[3]. Guo WJ, Yu EX, Liu LM, et al (2003) Comparison between chemoembolization combined with radiotherapy and chemoembolization alone for large hepatocellular carcinoma. World J Gastroenterol 9:1697-1701

[4]. Yamasaki T, Kurokawa F, Shirahashi H, et al (2002) Percutaneous radiofrequency ablation therapy for patients with hepatocellular carcinoma during occlusion of hepatic blood flow. Comparison with standard percutaneous radiofrequency ablation therapy. Cancer 95:2353-2360

[5]. Christiane Kulinna and Wolfgang Schima Imaging Features of Hepatic Metastases: CT and MR

[6]. Kopka L, Rodenwaldt J, Fischer U, et al (1996) Dual-phase helical CT of the liver: effects of bolus tracking and different volumes of contrast material. Radiology 201:321-326

[7]. Silverman PM, Brown B, Wray H, et al (1995a) Optimal contrast enhancement of the liver using helical (spiral) CT: value of SmartPrep. AJR Am J Roentgenol 164:1169-1171

[8]. Loyer EM, Chin H, DuBrow RA, et al (1999) Hepatocellular carcinoma and intrahepatic peripheral cholangiocarcinoma:enhancement patterns with quadruple phase helical CT. A comparative study. Radiology 212:866-875

[9]. Kopka L, Rodenwaldt J, Hamm BK (2000) Value of hepatic perfusion imaging for indirect detection of different liver lesions: feasibility study with multi-slice helical CT. Radiology 217(P):457

[10]. Oliver JH 3rd, Baron RL, Federle MP, et al (1997) Hypervascular liver metastases: do unenhanced and hepatic arterial phase CT images affect tumor detection? Radiology 205:709-715

[11]. Sheafor DH, Frederick MG, Paulson EK (1999) Comparison of unenhanced, hepatic arterial-dominant and portal venous-dominant phase helical CT for the detection of liver metastases in women with breast carcinoma. AJR Am J Roentgenol 172:961-968

[12]. Sica GT, Hoon J, Pablo RR (2000) CT and MR imaging of hepatic metastases. AJR Am J Roentgenol 174:691-698

[13]. Oliver JH 3rd, Baron RL, Federle MP (1998) Hypervascular liver metastases: do unenhanced and hepatic arterial phase CT images affect tumor detection? Radiology 209:585-586

[14]. Kim KE, Park MS, Bentley-Hibbert S, Baek SE, Kim YC, Kim MJ, Kim KW, Auh YH:Hepatocellular carcinoma: clinical and radiological findings in patients with chronic B viral hepatitis and chronic C viral hepatitis. Abdom Imaging 2012, 37:591-594.

[15]. Butt AS, Hamid S, Wadalawala AA, Ghufran M, Javed AA, Farooq O, Ahmed B, UI Haq T, Jafri W: Hepatocellular carcinoma in Native South Asian Pakistani population; trends, clinico-pathological characteristics \&differences in viral marker negative \& viralhepatocellular carcinoma.BMC Res Notes 2013, 6:137

[16]. Nimer Assy, Gattas Nasser, Agness Djibre, Zaza Beniashvili, Saad Elias, Jamal Zidan World J Gastroenterol 2009 Characteristics of common solid liver lesions and recommendations for diagnostic workup July 14; 15(26): 3217-3227

[17]. Buchman TG, Zuidema GD. The role of computed tomographic scanning in the surgical management of pyogenic hepatic abscess. Surg Gynecol Obstet 1981;1 53:1-9

[18]. Rubinson HA, Isikoff MB, Hill MC. Diagnostic imaging of hepatic abscesses: a retrospective analysis. AJR 1980;1 35: 735-740

[19]. David J. Lomas. The Liver. In: Grainger \& Allison's Diagnostic Radiology,5th ed Churchill Livingstone 2008.

[20]. Wilson SR, Withers CE. The Liver. In: Rumack CM, Wilson SR, Charboneau JW, editors. Diagnostic Ultrasound. 3rd edition. Elsevier Mosby; 2005.

[21]. Soyer P, Sirol M, Fargeaudou Y, Duchat F, Hamzi L, Boudiaf M, et al.Differentiation between true focal liver lesions and psudolesions in patients with fatty liver: evaluation of helical CT criteria. Eur Radiol 2010; 20: 1726-37.

[22]. Van Leeuven MS, Noordzij J, Feldberg MA, Hennipman AH, Doorneewaard H. Focal Liver lesions; characterization with triphasic computed tomography Radiology 1996; 201: 327-36.

[23]. Szklaruk J, Silverman PM, Chamsangavej C. Imaging in the diagnosis, staging,treatment and surveillance of hepatocellular carcinoma. AJR Am J Roentgenol 2003; 180: 441-54

[24]. Iannaccone R, Piacentini F, Murakami T, Paradis V, Belghiti J, Hori M, et al.Hepatocellular carcinoma in patients with nonalcoholic fatty liver disease:helical CT and MR imaging findings with clinical-pathologic comparison.Radiology 2007; 243: 422 30.

[25]. Iannaccone R, Laghi A, Catalano C, Rossi P, Mangiapane F, Murakami T, et al.Hepatocellular carcinoma, role of unenhanced and delayed phase multi detector row helical computed tomography in patients with cirrhosis. Radiology 2005;234: 460-7.

[26]. Bioulac-Sage P, Balabaud C, Bedossa P,Scoazec JY, Chiche L, Dhillon AP, et al: Pathological diagnosis of liver cell adenoma and focal nodular hyperplasia: Bordeaux update. J Hepatol 2007; 46: 521-527.

[27]. Hui-Xiong Xu, , Guang-Jian Liu, , Ming-De Lu, , Xiao-Yan Xie, MD, PhD, Zuo-Feng Xu, MD, Yan-Ling Zheng, Jin-Yu Liang, Characterization of Small Focal Liver Lesions Using Real-time Contrast-Enhanced Sonography Diagnostic Performance Analysis in 200 Patients J Ultrasound Med 2006; 25:349-361

[28]. Premashis Kar, Rajat JainImaging of Space Occupying Lesions of Liver Medicine Update-2011

[29]. Bluemke DA, Fishman EK. Spiral CT of the liver. AIR 1993; 160:787-792.

[30]. Zeman RK, Fox SH, Silverman PM, et al.Helical (spiral) CT of the abdomen. AJR 1993; 160:719-725.

[31]. Zeman RK, Zeiberg AS, Davros WJ, et al.Routine helical CT of the abdomen: image quality considerations. Radiology 1993;189:395-400

[32]. Bluemke DA, Urban BA, Fishman EK.Spiral CT of the liver: current applications.Semin Ultrasound CT MR 1994; 15:107-121.

[33]. Baron RL, Dodd GD III, Holbert BL, Oliver JH III, Cam B. Helical biphasic contrast CT in evaluation of hepatocellular carcinoma (abstr). Radiology 1994; 193(P):435.

[34]. Murakami T, Kim T, Oi H, et al. Detectability of hypervascular hepatocellular cancinoma by arterial phase images of MR and spinal CT. Acta Radiol 1995; 36:372-376.

[35]. Hollett MD, Brooke Jeffrey R, Nino-Murcia M, Jorgensen MJ, Harris DP. Dual-phase helical CT of the liver: value of arterial phase scans in the detection of small $(<1.5 \mathrm{~cm})$ malignant hepatic neoplasms. AJR 1995; 164:879-884. 
[36]. Bonaldi VM, Bret I'M, Reinhold C, Atni M. Helical CT of the liver: value ot an early hepatic arterial phase. Radiology 1995; 197: 357-363.37-39

[37]. Kihana Y, Tamuna 5, Yuki Y, et al. Optimal timing for delineation of hepatocellu- Ian carcinoma in dynamic CT. J Comput Assist Tomogn 1993; 17:719-722.

[38]. Yoshikawa J, Matsui 0, Kadoya M, et al. Delayed enhancement of fibrotic areas in hepatic masses: CT-pathologic correlation. I Comput Assist Tomogr 1992; 16:206-211.

[39]. Peterson MS, Baron RL, Dodd GD III, et al. Hepatic parenchymal perfusion defects detected with C-3TAP: imaging-pathologic correlation. Radology 1992; 185:149-155.

[40]. Davarpanah A.H., Weinreb J.C. The role of imaging in hepatocellular carcinoma: The present and future. J. Clin. Gastroenterol. 2013;47:S7-S10.

[41]. Robinson JG, Pollock TW. Computed tomography in the diagnosis and localization of intraabdominal abscesses. Am J Surg1980;140:783-786

[42]. Callen PW. Computed tomographic evaluation of abdominal and pelvic abscesses. Radiology 1979;1 31:171-175

[43]. American College of Radiology ACR Appropriateness Criteria, Clinical Condition: Suspected Liver Metastases Variant: Initial imaging test following detection of primary tumor

[44]. Chezmar JL, Rumancik WM, Megibow AJ, Hulnick DH, Nelson RC, Bernardino ME. Liver and abdominal screening in patients with cancer: CT versus MR imaging. Radiology 1988; 168: 43-7.

[45]. Jones EC, Chezmar JL, Nelson RC, Bernardino ME. The frequency and significance of small (less than or equal to $15 \mathrm{~mm}$ )hepatic lesions detected by CT. AJR 1992; 158(3):535-539.

[46]. Schwartz HL, Gandras EJ, Colangelo SM, et al. Prevalence and importance of small hepatic lesions found at CT in patients with cancer. Radiology 1999; 210(1):71-74.

[47]. Kruskal JB, Kane RA. Imaging of primary and metastatic livertumors. Surg Oncol Clin North Am 1996; 5(2):231-260.

[48]. Mahfouz AE, Hamm B, Mathieu D. Imaging of metastases to the liver. Eur Radiol 1996; 6(5):607-614.

[49]. Nies C, Leppek R, Sitter H, et al. Prospective evaluation of different diagnostic techniques for the detection of liver metastases at the time of primary resection of colorectal carcinoma. Eur J Surg 1996; 162(10):811-816

[50]. Van Leeuwen MS, Noordzij J, Feldberg MAM, et al. Focal liver lesions: characterization with triphasic spiral CT. Radiology 1996;201(2):327-336.

[51]. Van Hoe L, Baert AL, Gryspeerdt S, et al. Dual-phase helical CT of the liver: value of an early-phase acquisition in the differential diagnosis of noncystic focal lesions. AJR 1997; 168(5):1185-1192

[52]. Harvey CJ, Albrecht T. Ultrasound of focal liver lesions. Eur Radiol 2001; 11:1578-1593.

[53]. Wernecke K, Vassallo P, Bick U, Diederich S, Peters PE. The distinction between benign and malignant liver tumors on sonography: value of a hypoechoic halo. AJR Am J Roentgenol 1992; 159:1005-1009.

[54]. Paulson EK. Evaluation of the liver for metastatic disease.Semin Liver Dis 2001; 21:225-236.

[55]. Bree RL, Schwab RE, Neiman HL. Solitary echogenic spot in the liver: is it diagnostic of a hemangioma? AJR Am J Roentgenol $1983 ; 140: 41-45$.

[56]. Caturelli E, Pompili M, Bartolucci F, et al. Hemangioma-likelesions in chronic liver disease: diagnostic evaluation in patients Radiology 2001; 220:337-342

[57]. Stephanie R. Wilson, MD, Hyun-Jung Jang, MD, Tae Kyoung Kim, MD, Peter N. Burns, PhD J Diagnosis of Focal Liver Masses on Ultrasonography Comparison of Unenhanced and Contrast-Enhanced Scans Ultrasound Med 2007; 26:775-787

[58]. Klein D, Jenett M, Gassel HJ,Sandstede J, Hahn D (2004) Quantitative dynamic contrast-enhanced sonography of hepatic tumors. Eur Radiol 14:1082-1091 